\title{
Characterization and Physical Analysis of a 3,5-Xylenol Degradative Plasmid in Pseudomonas putida
}

\author{
By RAKESH K. JAIN, RONALD C. BAYLY* AND RONALDA. SKURRAY \\ Department of Microbiology, Monash University, Clayton, Victoria 3168, Australia
}

(Received 8 March 1984; revised 19 June 1984)

\begin{abstract}
Pseudomonas putida NCIB 9869 carries a transmissible plasmid pRA500 of approximately $500 \mathrm{~kb}$ which encodes the degradation of 3,5-xylenol via a gentisate pathway. Several mutant strains which were unable to utilize 3,5-xylenol were isolated and these strains either carried deleted derivatives of pRA500 or lacked plasmid DNA. Biochemical and restriction endonuclease analysis of the wild-type and mutant strains showed that the structural and/or regulatory genes for 3,5-xylenol metabolism were encoded within a $130-140 \mathrm{~kb}$ region of pRA500 and that, with the exception of the first enzyme of the pathway, 3,5-xylenol methylhydroxylase, all the enzymes were encoded within a $50-70 \mathrm{~kb}$ segment of that region. pRA500 also encoded for resistance to inorganic mercuric ions; the genes for this phenotype were located separately from those for the degradation of 3,5-xylenol.
\end{abstract}

\section{INTRODUCTION}

Aromatic compounds such as xylenols and cresols are by-products of the high temperature carbonization of coal (Dagley, 1978). With an increase in the use of coal as an energy source, such by-products will be found in increasing concentrations in the environment and it is important to understand how to maximize their microbial degradation and possible utilization to supply chemical feedstocks. Hopper \& Chapman (1971) and Hopper et al. (1971) have shown that 3,5-xylenol is metabolized by Pseudomonas putida NCIB 9869 to 3-methyl gentisate, which is cleaved by a gentisate 1,2-dioxygenase to 6-methylmaleylpyruvate; this compound is further metabolized to pyruvate and acetyl-CoA (Fig. 1 a). 3,5-Xylenol grown cells of the same P.putida strain also metabolized $m$-cresol via an analogous pathway. However, when $m$-cresol was used as a growth substrate, it was metabolized via a catechol meta-cleavage pathway and no gentisate 1,2-dioxygenase (E in Fig. 1a) was synthesized (Hopper \& Taylor, 1975).

The genetic information for the degradation of a wide variety of aromatic compounds is, in many pseudomonads, located on plasmids. A large plasmid of more than $300 \mathrm{~kb}$ was isolated from the 3,5-xylenol degrading (3,5-X $\mathrm{In}^{+}$) strain by Hopper \& Kemp (1980). The observation that spontaneously derived strains which had lost the 3,5-XIn ${ }^{+}$phenotype carried deleted forms of the large plasmid, together with the ability of the 3,5-XIn ${ }^{+}$phenotype to be transferred by conjugation, led these authors to propose that the genes encoding 3,5-xylenol degradation were located on the plasmid in $P$. putida. This communication reports the further characterization of this plasmid, which we have designated pRA500, and physical analysis of plasmids carried by newly isolated derivative strains which do not utilize $3,5-x y l e n o l\left(3,5-\mathrm{X} \ln { }^{-}\right)$.

\section{METHODS}

Bacterial strains, media and preparation of cell extracts. Bacterial strains, and their relevant phenotypes and plasmid complement are listed in Table 1. The 3,5-XIn ${ }^{+}$organism used was Pseudomonas purida NCIB 9869, which will be referred to as strain RA500. It was maintained on a basal salts minimal medium (MM) (Hegeman. 1966) containing 3,5-xylenol (2-5 mM): $3,5-X / n^{-}$strains were maintained on nutrient agar. 
(a)

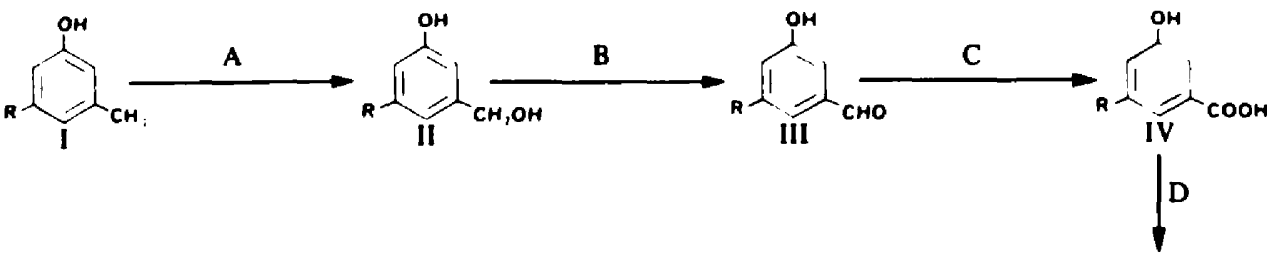

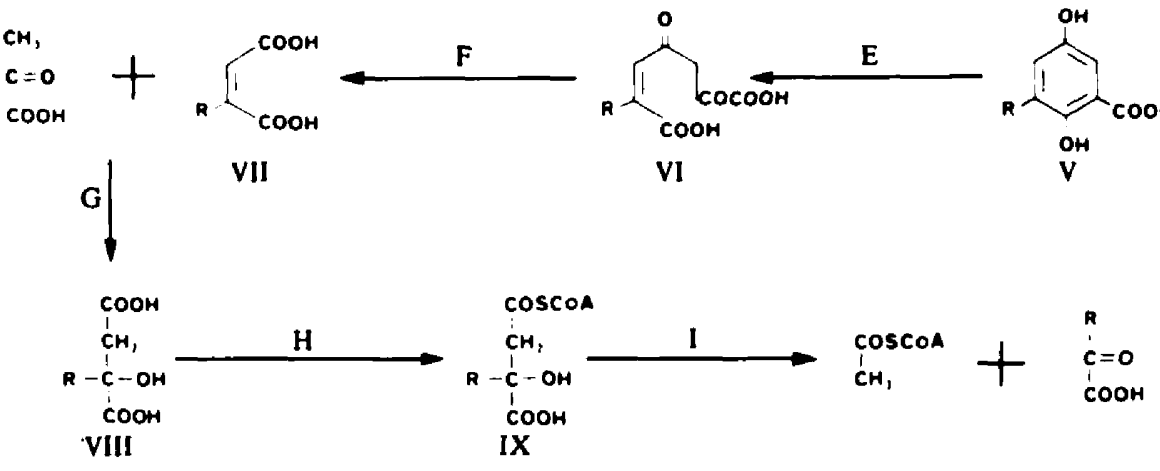

(b)

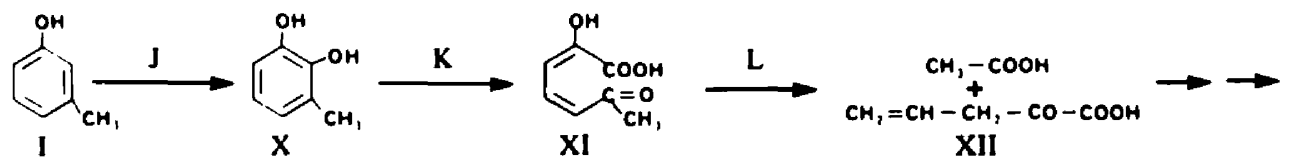

Fig. I. Pathway(s) of metabolism of 3,5-xylenol and $m$-cresol by $P$. putida NCIB 9869.

(a) Gentisate pathway. Enzymes shown are: A, 3,5-xylenol methylhydroxylase; B, alcohol dehydrogenase; $C$, aldehyde dehydrogenase; D, 3-hydroxy-5-methylbenzoate 6-hydroxylase; $E$, gentisate 1,2-dioxygenase; $F$, maleylpyruvate hydrolase; $G$, citraconase [( - )-citramalate hydro-lyase]; H, citramalate : coenzyme A transferase; I, citramaleyl-coenzyme A lyase system. Compounds shown are as follows. When $\mathbf{R}=\mathrm{CH}_{3}$ : I, 3,5-xylenol; II, 3-hydroxy-5-methylbenzyl alcohol; III, 3-hydroxy-5methylbenzaldehyde; IV, 3-hydroxy-5-methylbenzoate; V, 3-methylgentisate; VI, 6-methylmaleylpyruvate; VII, citraconate; VIII, citramalate; IX, citramaleyl-coenzyme $A$. When $\mathbf{R}=\mathbf{H}: \mathbf{I}, \boldsymbol{m}$-cresol; II, 3-hydroxybenzyl alcohol; III, 3-hydroxybenzaldehyde; IV, 3-hydroxybenzoate; V, gentisic acid; VI maleylpyruvate; VII, maleic acid; VIII, malic acid; IX, maleyl-coenzyme $A$.

(b) Initial steps of the meta-cleavage pathway. Enzymes shown are: J, phenol hydroxylase; $\mathbf{K}$, catechol 2,3-oxygenase; L, 2-hydroxy-6-ketohepta-2,4-dienoate hydrolase. Compounds shown are I, m-cresol; X, 3-methylcatechol; XI, 2-hydroxy-6-ketohepta-2,4-dienoate; XII, 2-ketopent-4-enoate.

Methods of cultivation, conditions of growth, induction of enzymes and preparation of cell extracts were as described previously (Poh \& Bayly, 1980) except that when cultures were grown in the presence of an aromatic compound, the incubation period was $6 \mathrm{~h}$ and cells were washed with $0.015 \mathrm{M}$-phosphate buffer (pH 7.4) and resuspended in $0.1 \mathrm{M}$-phosphate buffer $(\mathrm{pH} \mathrm{7.4)}$. Unless stated otherwise, the final concentration of aromatic compounds used either as growth substrates or as potential inducers was $2.5 \mathrm{mM}$. Resistance to inorganic mercuric salts $\left(\mathrm{Hg}^{r}\right)$ was determined as described by Pickup et al. (1983) using filter paper strips impregnated with $20-30 \mu \mathrm{l}$ of a $10 \mathrm{mg} \mathrm{ml}^{-1}$ solution of mercuric chloride. All cultures were grown at $30^{\circ} \mathrm{C}$.

Enzyme assays. 3,5-Xylenol methylhydroxylase (A in Fig. 1), alcohol dehydrogenase (B), aldehyde dehydrogenase (C), 3-hydroxy-5-methylbenzoate 6-hydroxylase (D), citraconase (G, EC 4.2.1.35), the citramalate system (H, EC 2.8.3.7, and I, EC 4.1.3.25) and p-cresol methylhydroxylase were assayed as described by Hopper \& Kemp (1980) with the exceptions that enzymes B, C and D were assayed using ultracentrifuged extracts and that enzyme $C$ was assayed at $340 \mathrm{~nm}$ as described previously by Poh \& Bayly (1980). Activity of enzyme B against p-hydroxybenzyl alcohol was determined at $370 \mathrm{~nm}$ (Keat \& Hopper, 1978b). Gentisate 1,2-dioxygenase (E, EC 1.13.11.4), was assayed by measuring the rate of formation of maleylpyruvate at $330 \mathrm{~nm}$ in a reaction mixture that contained $0.25 \mu \mathrm{mol}$ gentisate in $1 \mathrm{ml} 50 \mathrm{~mm}$-Tris/ $/ \mathrm{HCl}$ bufier (pH 7.4); the molar absorbance coefficient of maleylpyruvate at $330 \mathrm{~nm}$ was taken as $125001 \mathrm{~mol}^{-1} \mathrm{~cm}^{-1}$ (Poh \& Bayly, 1980). Maleylpyruvate hydrolase (F) and fumarylpyruvate hydrolase were assayed as described by Poh \& Bayly (1980). 
Phenol hydroxylase ( $J$ ) was assayed as described by Bayly \& McKenzie (1976) and catechol 2,3-oxygenase (K, EC 1.13.11 2) and 2-hydroxy-6-ketohepta-2,4-dienoate hydrolase (L) were assayed as described by Bayly \& Wigmore (1973). With the exceptions of 3,5-xylenol methylhydroxylase, p-cresol methylhydroxylase and phenol hydroxylase, which were assayed at $30^{\circ} \mathrm{C}$, all enzymes were assayed at $23^{\circ} \mathrm{C}$ using a Perkin-Elmer 552 spectrophotometer. Protein concentration in cell extracts was determined by the method of Lowry using serum albumin as a standard.

Isolation of 3,5-XIn-deritatives. Two methods were used to isolate derivatives of strain RA500 which could not grow on 3,5-xylenol. In the first method, nutrient broth $(10 \mathrm{ml})$ was inoculated with $10^{6}-10^{7}$ cells of strain RA 500 and the culture was grown with aeration to stationary phase; this represented one cycle. After three cycles, the culture was diluted in $\mathrm{MM}$ and approximately $10^{2}$ cells were jnoculated onto nutrient agar plates. One hundred single colonies were picked and patched onto nutrient agar plates which, after incubation overnight, were replicaplated onto MM agar plates containing 3,5-xylenol as sole carbon source: 3,5-Xln-derivatives were selected for further purification and characterization. The second method was essentially as described by Chakrabarty (1972) with the exceptions that the concentration of mitomycin $C$ was $1 \mu \mathrm{g} \mathrm{ml^{-1 }}$ and three cycles of mitomycin $C$ treatment were carried out. Derivatives unable to grow on 3.5-xylenol were further characterized by replica-plating colonies onto $\mathrm{MM}$ agar plates containing one of $m$-hydroxybenzyl alcohol, $m$-hydroxybenzaldehyde, $m$-hydroxybenzoate or gentisate. The ability of these derivatives to revert to growth on 3,5-xylenol was determined by inoculating approximately $10^{9}-10^{10}$ cells from a washed, overnight nutrient broth culture onto MM agar plates containing 3,5-xylenol; plates were incubated for $7 \mathrm{~d}$.

Isolation of plasmid DNA, restriction endonuclease digestion, agarose gel electrophoresis and sizing of plasmids. Plasmid DNA was isolated and electrophoresed in $0.7 \%(w / v)$ agarose (Sigma, Type II) as described by Wheatcroft \& Williams (1981). The gels were stained with ethidium bromide ( $5 \mu \mathrm{g} \mathrm{ml}^{-1}$ ) and destained in distilled water. DNA bands were visualized and photographed as described by Ray \& Skurray (1983). For endonuclease digestion, plasmid DNA was purified by sucrose density centrifugation (Wheatcroft \& Williams, 1981) and digested separately with EcoRI (Boehringer, Australia), HindIII and AhallI (New England Biolabs, USA) according to Davis et al. (1980) or to the supplier's instructions. Depending on their size, DNA fragments were electrophoresed in either $0.7 \%$ or $1.2 \%(w / v)$ agarose in Tris/acetate/EDTA buffer (Johnson \& Grossman, 1977) using a horizontal submerged system. The size of restriction fragments was determined, using as standards $H$ indIII and EcoRI-HindlII double digests of $\lambda$ DNA (Miles Laboratories, USA) (Daniels et al., 1983) and HindIII digests of pWW0 (Downing \& Broda, 1979). The relationship kb-0.67 versus migration distance was used to calculate the molecular sizes of the fragments (Bearden, 1979). Estimates of the size of the plasmids are the values obtained from two separate digestions. with the same enzyme(s).

Conjugation. The transfer of $3,5-\mathrm{XIn}^{+}$and $\mathrm{H}_{\mathrm{g}}$ ' phenotypes was achieved by plate matings. Equal volumes of overnight nutrient broth cultures were mixed on nutrient agar plates, which were incubated overnight, and following resuspension of the bacterial growth in $\mathrm{MM}$, appropriate dilutions were plated onto selective plates. For transfer of the 3,5-XIn ${ }^{+}$phenotype, selection was on 3,5-xylenol and streptomycin plates; for transfer of the $\mathrm{Hg}^{r}$ phenotype, selection was on nutrient agar and streptomycin plates with detection of $\mathbf{H g}_{\mathbf{g}}{ }^{\mathbf{r}}$ colonies as described above.

\section{RESULTS}

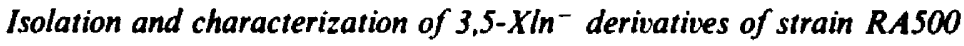

Approximately fifty $3,5-\mathrm{XIn}$ - strains were isolated either spontaneously, by growth in nutrient broth, or by growth in the presence of mitomycin $C$. The frequency of loss of the 3,5XIn ${ }^{+}$phenotype following growth on nutrient broth was $5-8 \%$ and this increased to $40-50 \%$ when mitomycin $\mathrm{C}$ was present during growth. Agarose gel electrophoresis revealed that each of the 3,5-XIn- derivatives isolated contained a single species of plasmid DNA which was smaller than pRA500. From this analysis, five 3,5-X $\ln ^{-}$strains were selected on the basis that they carried plasmids of different sizes. These strains and their plasmid complements are shown in Table 1. No derivatives of strain RA500 were isolated that had been cured of pRA500. However, mitomycin C treatment of strain RA502 gave rise to an $\mathrm{Hg}^{\mathbf{3}}$ strain (RA713, Table 1 ) which did not show any plasmid band after agarose gel electrophoresis. With the exception of one strain, RA573(pRA505), none of the derivatives could grow on $m$-hydroxybenzyl alcohol, $m$ hydroxybenzaldehyde, $m$-hydroxybenzoate or gentisate (Table l). No spontaneous revertants of any of these six derivatives arose on MM agar plates containing 3,5-xylenol.

The restriction digests of pRA500 and its deleted derivatives pRA501 to pRA505 with $H i n d I I I$ are shown in Fig. 2. The estimated size of pRA500 from analysis of HindIII and EcoRI digests was 500-515 and 480-490 kb, respectively. On the basis of HindIII digests, the sizes of 
Table 1. P. putida strains

\begin{tabular}{|c|c|c|c|c|}
\hline Strain & Relevant phenotype* & Plasmid & Parent strain(s) & Derivation or source \\
\hline $\begin{array}{l}\text { RA500 } \\
\text { (NCIB 9869) }\end{array}$ & $\begin{array}{l}\text { 3,5-XIn+ } \mathrm{Mbe}^{+} \mathrm{Mbd}^{+} \mathrm{Mba}^{+} \\
\mathrm{Gen}^{+} \mathrm{Mcr}^{+} \mathrm{Hg}_{\mathrm{g}^{\prime}}\end{array}$ & pRA500 & - & P. J. Chapman \\
\hline RA501 & $\begin{array}{l}\text { 3.5-XIn- } \mathrm{Mbe}^{-} \mathrm{Mbd}^{-} \mathrm{Mba}^{-} \\
\mathrm{Gen}^{-} \mathrm{Mcr}^{+} \mathrm{Hg}^{\prime}\end{array}$ & pRA50I & RASO0 & Growth in nutrient broth \\
\hline $\begin{array}{l}\text { RA502 } \\
\text { RA517 } \\
\text { RA522 } \\
\text { RA573 }\end{array}$ & $\begin{array}{l}\text { As RA50I } \\
\text { As RA50I } \\
\text { As RA50I } \\
3,5-\mathrm{XIn}^{-} \mathrm{Mbe}^{+} \mathrm{Mbd}^{+} \mathrm{Mba}^{+} \\
\mathrm{Gen}^{+} \mathrm{Mcr}^{+} \mathrm{He}^{\prime}\end{array}$ & $\begin{array}{l}\text { pRA502 } \\
\text { pRA503 } \\
\text { pRA504 } \\
\text { pRA505 }\end{array}$ & $\begin{array}{l}\text { RA500 } \\
\text { RA500 } \\
\text { RA500 } \\
\text { RA500 }\end{array}$ & $\begin{array}{l}\text { Mitomycin C treatment } \\
\text { Mitomycin C treatment } \\
\text { Growth in nutrient broth } \\
\text { Mitomycin C treatment }\end{array}$ \\
\hline RA711 & $\begin{array}{l}\text { 3,5-XIn } \mathrm{Mbe}^{+} \mathrm{Mbd}^{+} \mathrm{Mba}^{+} \\
\mathrm{Gen}^{+} \mathrm{Mcr}^{+} \mathrm{Hg}^{\prime} \mathrm{Str}^{\prime} \mathrm{Trp}^{-}\end{array}$ & pRA500 & RA500 $\times$PaW 340 & Conjugation \\
\hline $\mathbf{R A} 713$ & $\begin{array}{l}\text { 3,5-Xln- } \mathrm{Mbe}^{-} \mathrm{Mbd}^{-} \mathrm{Mba}^{-} \\
\mathrm{Gen}^{-} \mathrm{Mcr}^{+} \mathrm{Hg}^{\mathrm{s}}\end{array}$ & - & RASO2 & Mitomycin C treatment \\
\hline RA741 & $\begin{array}{l}\text { 3,5-Xln- } \mathrm{Mbe}^{-} \mathrm{Mbd}^{-} \mathrm{Mba}^{-} \\
\mathrm{Gen}^{-} \mathrm{Mcr}^{+} \mathrm{Hg}^{2} \mathrm{Str}^{r}\end{array}$ & - & RA713 & Spontaneous selection for Strr \\
\hline RA745 & $\begin{array}{l}\text { 3.5-XIn+ } \mathrm{Mbe}^{+} \mathrm{Mbd}^{+} \mathrm{Mba}^{+} \\
\mathrm{Gen}^{+} \mathrm{Mcr}^{+} \mathrm{Hg}^{\prime} \mathrm{Str}^{\mathrm{r}}\end{array}$ & pRAS00 & RA500 $\times$ RA741 & Conjugation \\
\hline $\mathrm{PaW} 340$ & $\begin{array}{l}\text { 3,5-Xln- } \mathrm{Mbe}^{-} \mathrm{Mbd}^{-} \mathrm{Mba}^{-} \\
\text {Gen }^{-} \mathrm{Mcr}^{-} \mathrm{Hg}^{*} \mathrm{Str}^{r} \text { Trp- }\end{array}$ & - & PaWl & P. A. Williams \\
\hline
\end{tabular}

- Phenotype designations: $3,5-\mathrm{Xln}{ }^{+}, \mathrm{Mbe}^{+}, \mathrm{Mbd}^{+}, \mathrm{Mba}^{+}, \mathrm{Gen}^{+}$and $\mathrm{Mcr}^{+}$denote the ability to grow on 3,5xylenol, $m$-hydroxybenzyl alcohol, $m$-hydroxybenzaldehyde, $m$-hydroxybenzoate, gentisate and $m$-cresol, respectively, as sole carbon source: $\mathrm{Hg}^{r}$ and $\mathrm{Str}^{r}$ denote resistance to mercuric ions and streptomycin $\left(250 \mu \mathrm{g} \mathrm{ml} \mathbf{~}^{-1}\right)$, respectively: $\operatorname{Trp}^{-}$denotes auxotrophy for tryptophan.

$\uparrow$ P. J. Chapman, Department of Biochemistry, College of Biological Sciences, University of Minnesota, St Paul, USA; P. A. Williams, Department of Biochemistry and Soil Science, University College of North Wales, Bangor, UK.

the derivative plasmids pRA501 to pRA505 were 300-310, 155-160, 290-300, 335-350 and 415$425 \mathrm{~kb}$, respectively; EcoRI digests gave similar values. A diagrammatic representation and comparison of the profiles of HindIll-generated fragments of pRA500 (the total number of bands detected on gel electrophoresis was 48) with those from pRA501, pRA502, pRA503 and pRA504 (Fig. 3) showed that either all or a fragment(s) of bands 2, 3, 5, 6, 9, 10, 12, 18, 20, 24, 27,29 and 46, totalling $130-140 \mathrm{~kb}$, were missing from each of these plasmids. The HindIII profile of pRA505 (Fig. 3) showed that all or a fragment(s) of bands 2, 3, 5 and 18 of pRA500, totalling 70-80 kb, were absent. Restriction analysis of pRA500 to pRA505 was also carried out with AhallI; this enzyme gave far fewer bands (23 with pRA500) as compared to HindIII and EcoRI. Although an accurate assessment of the size of the plasmids could not be made from the AhallI digests, due to some fragments being more than $50 \mathrm{~kb}$, the values obtained were consistent with those obtained using HindIII and EcoRI.

Plasmid pRA500 was conjugally transferred from strain RA500 to P. putida PaW 340 and to strain RA741 (Table 1) by selection for growth on 3,5-xylenol. Transconjugants arose at a frequency of approximately $10^{-6}$ per donor cell. Strains RA711 and RA745 (Table 1) are representative transconjugants from these transfers. HindIII and EcoRI digestion of plasmid DNA isolated from these two transconjugant strains showed them to possess plasmids indistinguishable from pRA500. In addition to showing the 3,5-XIn ${ }^{+}$phenotype, strains RA711 and $\mathrm{RA} 745$ were $\mathrm{Hg}^{\prime}$, suggesting that $\mathrm{Hg}^{r}$ is encoded on pRA500. Since $\mathrm{Hg}^{r}$ could still be conjugally transferred from strains RA501, RA502, RA517, RA522 and RA573, it was concluded that not only is the region encoding $\mathrm{Hg}^{\mathrm{r}}$, but also that for transfer function(s) (the $\mathrm{Tra}^{+}$region), retained on the plasmids pRA501, pRA502, pRA503, pRA504 and pRA505 carried by these strains.

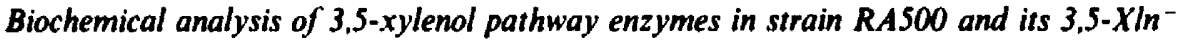 derivatives}

The 3,5-X $\mathrm{In}^{-}$derivatives were analysed to determine if the plasmid deletions or plasmid loss in those derivatives were associated with the loss of any of the enzymes from A to I (Fig. Ia). The 
strain of $P$. putida NCIB 9869 used in this study (RA500) showed some differences to the strain used by Hopper \& Kemp (1980). In the strain used in the present study, enzymes B and C were synthesized constitutively to high levels when either lactate, glutamate or succinate was the sole carbon source, and were not further inducible by either 3,5-xylenol, $m$-hydroxybenzyl alcohol (Table 2), $m$-hydroxybenzaldehyde, $m$-hydroxybenzoate or gentisate (data not shown). Hopper \& Kemp (1980) reported that when their strain was grown on glutamate these enzymes were synthesized constitutively to about $10 \%$ of the level obtained with growth on $3,5-x y l e n o l$. In addition, we found that growth of strain RA500 on m-cresol elicited both the gentisate and catechol meta-cleavage pathway enzymes shown in Fig. I $(a, b)$, whereas Hopper \& Taylor (1975) reported that, under the same condition, the strain of $P$. putida used in their studies synthesized only enzymes of the latter pathway. The reason for these differences is not known.

Activities of enzymes elicited during growth of strains RA500 and RA573(pRA505) on lactate and in the presence of either 3,5-xylenol or $m$-hydroxybenzyl alcohol are shown in Table 2: approximately the same activities were obtained when either $m$-hydroxybenzaldehyde, $m$ hydroxybenzoate or gentisate was used in the growth medium (data not shown). When the transconjugant strain RA711 (pRA500) was grown either in lactate or in the presence of 3,5xylenol, the activities of the enzymes synthesized were the same as those in strain RAS00 (data not shown). No activities of enzymes A to I (Fig. $1 a$ ) were detected when strains RA501, RA502, RA517, RA522 and RA713 were grown either on lactate or in the presence of 3,5-xylenol, $m$ hydroxybenzoate, gentisate or $m$-cresol; growth with the latter compound elicited the catechol meta-cleavage enzymes $J$ to $L$ (Fig. $\mid b$ ). Growth of these strains in the presence of $\mathrm{m}$ hydroxybenzyl alcohol or $m$-hydroxybenzaldehyde resulted in the synthesis of an alcohol dehydrogenase activity only. However, a comparison of the ratios of this activity against $o-, m-$ and p-hydroxybenzyl alcohol to that in strains RA500 and RA573 revealed that at least two alcohol dehydrogenases are present in strain RAS00 and that the alcohol dehydrogenase present in 3,5-XIn- derivatives is not encoded on pRA500 (data not shown). Keat \& Hopper (1978b) have reported that three alcohol dehydrogenases are synthesized in this strain.

The biochemical analysis of the 3,5-X $\ln ^{-}$derivative strains revealed that the regulatory and/or structural genes encoding enzymes $A$ to $I$ are located within a $130-140 \mathrm{~kb}$ region of pRA 500 which was deleted in each of pRA501 to pRA504. Of the genes encoding enzymes $A$ to $I$ (Fig. $1 a$ ), only the gene(s) for enzyme $A$ is absent from pRA505 and this plasmid had the smallest deletion of the five derivatives of pRA500 examined.

When strain RA500 was grown in the presence of $m$-cresol instead of 3,5-xylenol, enzymes A to $F$ (G to I not assayed) were present at about $70 \%$ of the level obtained with growth in the presence of 3,5-xylenol and, in addition, the catechol meta-cleavage pathway enzymes phenol hydroxylase ( $\mathrm{J}$ in Fig. 1 b), catechol 2,3-oxygenase $(\mathrm{K})$ and 2-hydroxy-6-ketohepta-2,4-dienoate hydrolase (L) were induced to high levels (data not shown). Growth of the transconjugant strain RA711 in the presence of $m$-cresol elicited enzymes $A$ to $F$ ( $G$ to I not assayed) but not enzymes $J$ to $\mathrm{L}$ and it is concluded that the genes encoding these latter enzymes are not located on pRA500.

\section{Identification of other enzymes encoded on pRA500}

Fumarylpyruvate hydrolase is an essential enzyme in micro-organisms which metabolize gentisate to fumarate and pyruvate via maleylpyruvate and fumarylpyruvate (Lack, 1961: Tanaka et al., 1957). Fumarylpyruvate hydrolase does not appear to be required in Pseudomonas alcaligenes NCIB 9867, in which maleylpyruvate and its analogues are metabolized by a maleylpyruvate hydrolase ( $F$ in Fig. $1 a$ ), although both enzymes are synthesized in this strain (Poh \& Bayly, 1980). A similar situation exists in $P$. putida strain RA500. We have detected a fumarylpyruvate hydrolase activity in strains RA500 and RA573(pRA505) grown in the presence of either 3,5-xylenol, $m$-hydroxybenzyl alcohol, $m$-hydroxybenzaldehyde, $m$-hydroxybenzoate or gentisate (data not shown) but such activity was not detected in strains RA501, RA502, RA517, RA522 or RA713. Activity of fumarylpyruvate hydrolase was also detected in strain RA711(pRA500) grown in the presence of 3,5-xylenol. These results indicate that the gene(s) for fumarylpyruvate hydrolase is located on pRA500 within the region encoding enzymes $B$ to $I$. 


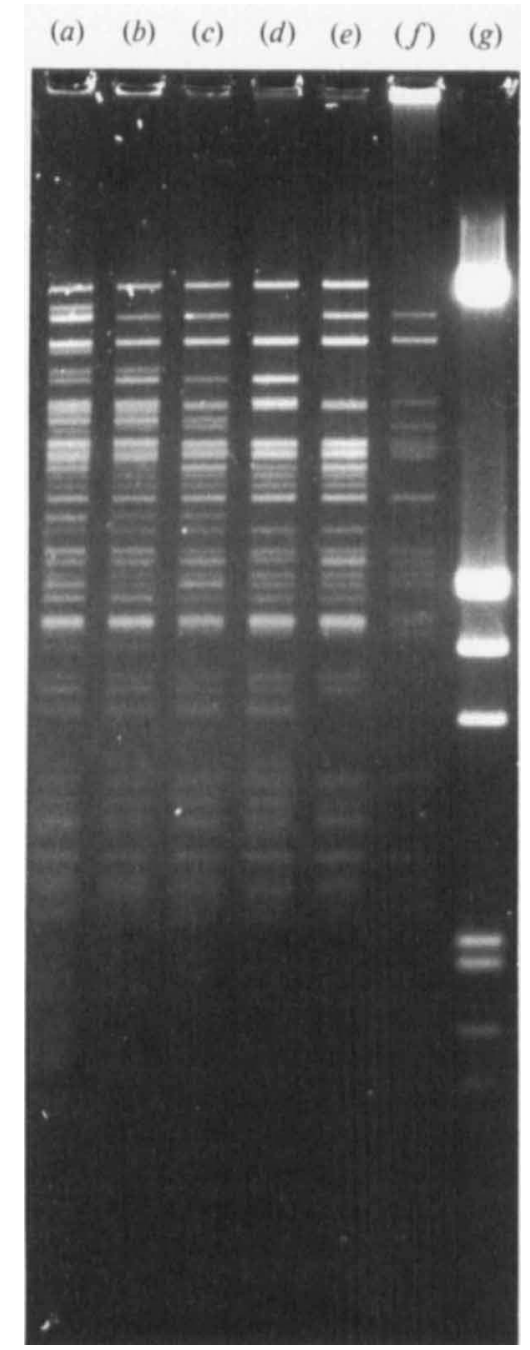

Fig. 2. Agarose gel electrophoresis of HindIII restriction endonuclease digests of pRA500 and its deleted derivatives. (a) pRA500. (b) pRA505, (c) pRA504, (d) pRA501, (e) pRA503, ( $(\Omega$ pRA502, (g) HindIII-EcoRI digest of $\lambda$ DNA as the standard.

Hopper \& Taylor (1975) reported that the strain of $P$. putida they used grew on p-cresol via its degradation by an ortho-cleavage pathway. Keat \& Hopper (1978a) showed that this strain synthesized two p-cresol methylhydroxylases, one during growth on 3,5-xylenol and the other during growth on p-cresol; neither activity was detected in succinate-grown cells. When grown on lactate, strain RA500 demonstrated a p-cresol methylhydroxylase activity. This activity did not increase during growth either on or in the presence of 3,5-xylenol, but when p-cresol replaced 3,5-xylenol, the activity increased approximately twofold (Table 3). Strains RA501(pRA501), RA502(pRA502), RA517(pRA503), RA522(pRA504) and RA713 showed p-cresol methylhydroxylase activity only when grown on or in the presence of $p$-cresol. As the constitutive activity was present in strain RA573(pRA505) but not in strains RA501(pRA501), RA502(pRA502), RA517(pRA503), RA522(pRA504) and RA713, the gene(s) encoding this enzyme must be located within the region of pRA500 which encodes enzymes $B$ to $I$. Analysis of the transconjugant strain RA711(pRA500) showed that only a constitutive p-cresol methyl- 


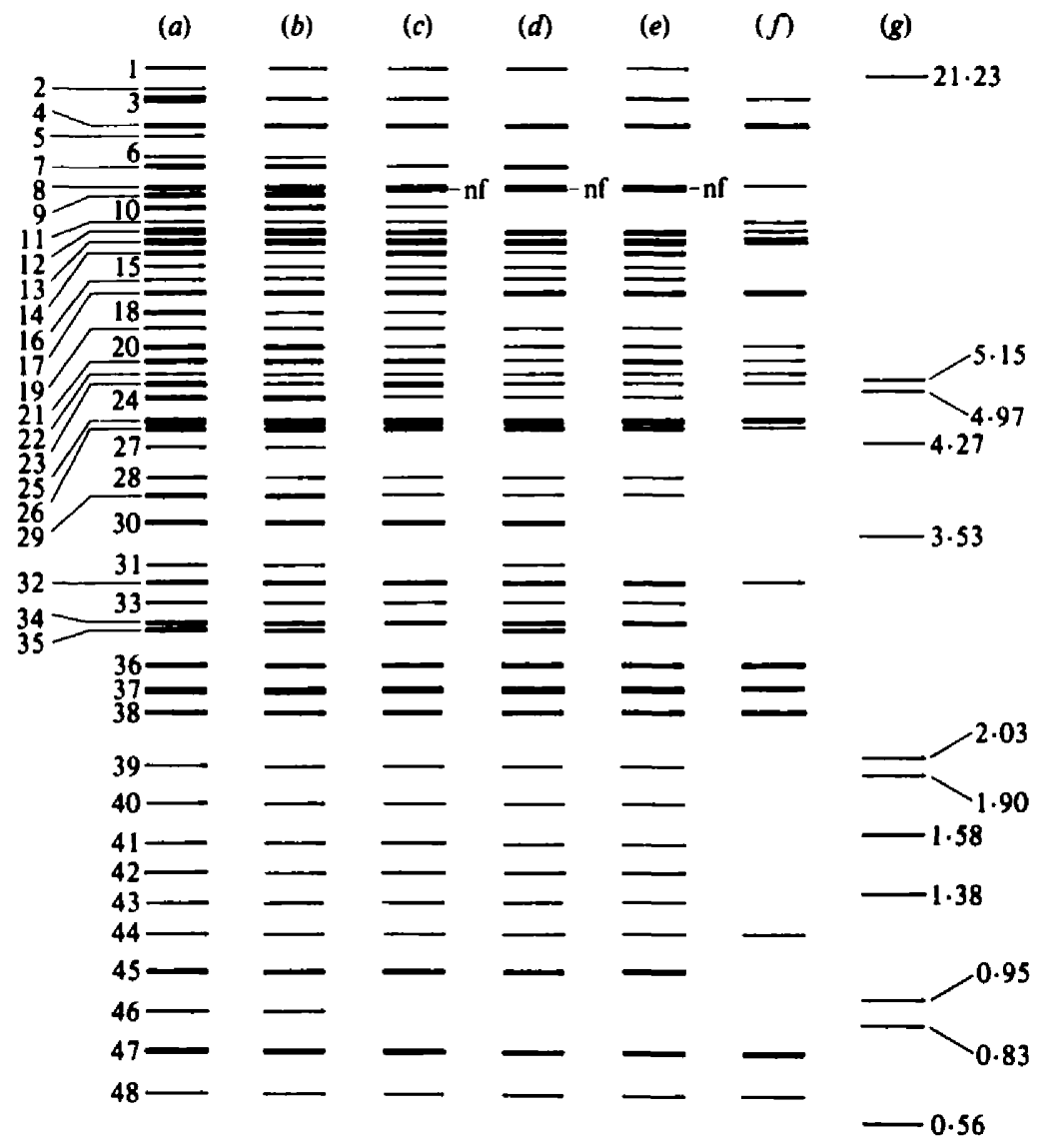

Fig. 3. Diagrammatic representation of agarose gel electrophoresis of HindIII digests of pRA500 and its deleted derivatives. The representation is constructed from several gels of $0.7 \%$ and $1.2 \%(w / v)$ agarose. (a) pRA500, (b) pRA505, (c) pRA504, (d) pRA501, (e) pRA 503, ( $)$ pRA502, (g) HindIII-EcoRI digest of $\lambda$ DNA as the standard; sizes, in $k b$, are shown on the right. Novel fragments are designated nf. In pRA500, bands $4,7,8,9,10,14,17,18,20,21,23,24,26,29,30,32,34,35,36,38,45$ and 47 have been assessed as doublets and bands $3,12,13,25$ and 37 have been assessed as triplets and are represented as thick lines.

hydroxylase activity was present, as growth of this strain either on, or in the presence of, $p$-cresol did not elevate the activity. It was concluded that the inducible p-cresol methylhydroxylase is not encoded on pRA500. This was confirmed by the fact that only an inducible p-cresol methylhydroxylase activity was present in the plasmid-free strain RA713 (Table 3).

\section{DISCUSSION}

The absence of activities of enzymes A to I (Fig. 1a) in strains RA501, RA502, RA517 and RA522, which carry the deleted plasmids pRA501 to pRA504, respectively, shows that the regulatory and/or structural genes for the degradation of 3,5-xylenol are plasmid-encoded; this confirms the finding of Hopper \& Kemp (1980). Although strains with mutations in or near the structural or regulatory genes of the 3,5-xylenol pathway have not been isolated, the enzyme analyses of strains presented here provide some information on the regulation of the synthesis of enzymes $A$ to $I$. The genes encoding these enzymes appear to be located in at least three regulatory units. As the alcohol and aldehyde dehydrogenases (B and $C$ ) are constitutively synthesized and are not further inducible they must be regulated separately to the xylenol 
Table 2. Specific activities of 3,5-xylenol pathway enzymes in strains RA500 and RA573 when grown on lactate or in the presence of either 3,5-xylenol or m-hydroxybenzyl alcohol

Specific activities are expressed as $\mu \mathrm{mol}$ substrate metabolized $\mathrm{min}^{-1}$ (mg protein) ${ }^{-1}$, except for that of 3,5-xylenol methylhydroxylase (A), which is expressed as $\mu \mathrm{mol}$ oxygen consumed $\mathrm{min}^{-1}$ ( $\mathrm{mg}$ dry wt cells) ${ }^{-1}$. The values listed are the means of values from two separate experiments.

\begin{tabular}{|c|c|c|c|c|c|c|c|c|c|}
\hline & & 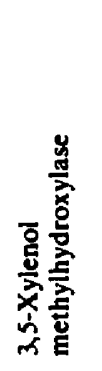 & 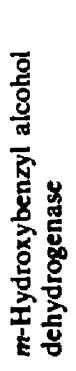 & 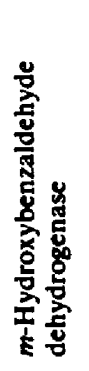 & 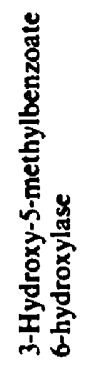 & 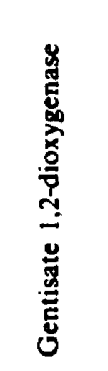 & 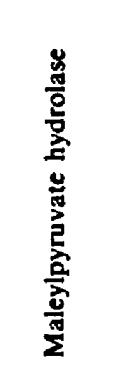 & 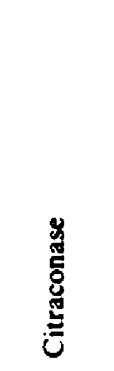 & 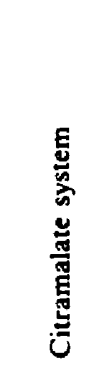 \\
\hline Strain & Carbon source & A & B & C & D & $\mathbf{E}$ & F & G & $\mathbf{H}+\mathbf{I}$ \\
\hline 10 & $\begin{array}{l}\text { Lactate } \\
\text { Lactate }+3,5 \text {-xylenol } \\
\text { Lactate }+m \text {-hydroxybenzyl alcohol }\end{array}$ & $\begin{array}{l}0.02 \\
0.08 \\
0.05\end{array}$ & $\begin{array}{l}0.58 \\
0.79 \\
0.62\end{array}$ & $\begin{array}{l}0.37 \\
0.29 \\
0.27\end{array}$ & $\begin{array}{c}<0.001 \\
0.09 \\
0.06\end{array}$ & $\begin{array}{c}<0.005 \\
1.32 \\
0.97\end{array}$ & $\begin{array}{c}<0.001 \\
0 \cdot 10 \\
0.08\end{array}$ & $\begin{array}{c}<0.005 \\
0.37 \\
0.41\end{array}$ & $\begin{array}{c}<0.001 \\
0.04 \\
0.03\end{array}$ \\
\hline 573 & $\begin{array}{l}\text { Lactate } \\
\text { Lactate }+3,5 \text {-xylenol } \\
\text { Lactate }+m \text {-hydroxybenzyl alcohol }\end{array}$ & $\begin{array}{l}<0.001 \\
<0.001 \\
<0.001\end{array}$ & $\begin{array}{l}0.60 \\
0.41 \\
0.48\end{array}$ & $\begin{array}{l}0.26 \\
0.33 \\
0.37\end{array}$ & $\begin{array}{c}<0.001 \\
<0.001 \\
0.08\end{array}$ & $\begin{array}{l}<0.005 \\
<0.005 \\
0.73\end{array}$ & $\begin{array}{c}<0.001 \\
<0.001 \\
0.09\end{array}$ & $\begin{array}{l}<0.005 \\
<0.005 \\
0.32\end{array}$ & $\begin{array}{c}<0.001 \\
<0.001 \\
0.03\end{array}$ \\
\hline
\end{tabular}

Table 3. Specific activity of p-cresol methylhydroxylase in strains RA500, RA573, RA501 and RATI3

Specific activity is expressed as $\mu \mathrm{mol}$ oxygen consumed $\min ^{-1}$ (mg protein) ${ }^{-1}$.

\begin{tabular}{|c|c|c|c|c|c|c|}
\hline Strain & $\begin{array}{l}\text { Carbon } \\
\text { source }\end{array}$ & Lactate & $\begin{array}{c}\text { Lactate + } \\
\text { 3,5-xylenol }\end{array}$ & $\underset{p \text {-cresol }}{\text { Lactate }}$ & 3,5-Xylenol & $p$-Cresol \\
\hline $\begin{array}{l}\text { RA500 } \\
\text { RA573 } \\
\text { RA501" } \\
\text { RA713 } \\
\text { RA711 }\end{array}$ & & $\begin{array}{c}0.10 \\
0.10 \\
<0.001 \\
<0.001 \\
0.06\end{array}$ & $\begin{array}{c}0.12 \\
0.12 \\
<0.001 \\
<0.001 \\
0.05\end{array}$ & $\begin{array}{l}0.23 \\
0.19 \\
0.10 \\
0.11 \\
0.06\end{array}$ & $\begin{array}{c}0.10 \\
\text { NT } \\
\text { NT } \\
\text { NT } \\
0.07\end{array}$ & $\begin{array}{l}0.19 \\
0.20 \\
0.11 \\
0.09 \\
0.07\end{array}$ \\
\hline
\end{tabular}

NT. Not tested.

- Strains RA502, RA517 and RA522 gave similar results to strain RA501.

methylhydroxylase (A), which is partially constitutive and further inducible. Whether the genes for the dehydrogenases are regulated separately is not known. Enzymes D to I are strictly inducible and they therefore must be located in a different regulatory unit(s) to those of enzymes $A$ to $C$; however, with the data available, we are unable to state whether $D$ to $I$ exist in one or more regulatory units.

The inducer(s) of enzymes $A$ and $D$ to I have not been identified. As shown by Hopper \& Kemp (1980), and confirmed in this study, growth on any of the analogues of the pathway intermediates resulted in approximately the same activities of enzymes $A$ to I. It seems unlikely that 3,5-xylenol acts as inducer of enzymes $D$ to I as none of those enzymes were induced when strain RA573(pRA505), which is deficient in the xylenol methylhydroxylase, was grown in the presence of 3,5-xylenol.

A comparison of the HindIIl restriction patterns of pRA500 and pRA501 to pRA504 revealed that common bands or fragments of bands of pRA500 totalling 130-140 kb were absent from each of pRA501 to pRA504 and we therefore conclude that the genes encoding enzymes A to I are located within that region of pRA500. Since the restriction pattern of pRA505 shows that $70-80 \mathrm{~kb}$ of pRA500 were absent and since the strain, RA573, carrying this plasmid retained all 
the 3,5-xylenol degrading enzymes except $A$, the genes encoding enzymes $B$ to I must be located within the remaining $50-70 \mathrm{~kb}$ of the region deleted from pRA501 to pRA504. Similarly, the absence of fumarylpyruvate hydrolase and the constitutive $p$-cresol methylhydroxylase in strains RA501, RA502, RA517 and RA522, and their presence in strain RA573, show that these enzymes are encoded within the same segment of pRA500 as are enzymes B to $I$. The conclusions drawn from the results of the restriction endonuclease digestions of pRA500 and its deleted derivatives should be viewed with caution due to the difficulties inherent in assessing the molecular size of large plasmids. Pickup \& Williams (1982) have drawn attention to points such as the errors in sizing large fragments, the assignment of the wrong multiplicity to bands and the difficulty in resolving bands in some areas of a gel; all these problems were encountered in the present study.

Since strain RA502 still retains resistance to inorganic mercuric salts and the ability to transfer $\mathrm{Hg}^{r}$ ( $\mathrm{Tra}^{+}$region), the genes encoding these phenotypes must be located within the 155$160 \mathrm{~kb}$ of pRA500 retained by pRA502, which indicates that 3,5-xylenol degradative genes encoded on pRA500 are located on a separate region to those for $\mathrm{Hg}^{\mathrm{r}}$ and $\mathrm{Tra}^{+}$.

One of the approaches to a more detailed analysis of the regulation of synthesis of the 3,5xylenol degradative enzymes is to clone the genes of this pathway from pRA500. Such an approach is in progress using broad host-range plasmid and cosmid vectors.

We thank John Hughes for stimulating discussions during this study. This project was supported, in part, by the Australian Research Grants Scheme, Grant no. D28015161I and by a Monash University Special Research Grant no. MS/84. R.K.J. was supported by a Monash Graduate Scholarship.

\section{REFERENCES}

BAyly, R. C. \& MCKenziE, D. I. (1976). Catechol oxygenases of Pseudomonas putida mutant strains. Journal of Bacteriology 127, $1098-1107$.

BAYLY, R. C. \& WIGMORE, G. J. (1973). Metabolism of phenol and cresols by mutants of Pseudomonas purida. Journal of Bacteriology 113, 1112-1120.

BEARDEN, J. C., JR (1979). Electrophoretic mobility of high-molecular-weight, double-stranded DNA on agarose gels. Gene 6, 221-234.

Chakrabarty, A. M. (1972) Genetic basis of the biodegradation of salicylate in Pseudomonas. Journal of Bacteriology 112, 815-823.

DAgley, S, (1978). Pathways for the utilization of organic growth substrates. In The Bacteria, vol. VI: Bacterial Ditersity, pp. $305-388$. Edited by L. N. Ornston \& J. R. Sokatch. New York: Academic Press.

Daniels, D. L., Schroeder, J. L. \& Szyaalski, W. (1983). A molecular map of coliphage lambda. In Lambda II, pp. 469-517. Edited by J. W. Roberts, F. W. Stahl \& R. A. Weisberg. New York: Cold Spring Harbor Laboratory.

DA vis, R. W., Botstein, D. \& Roth, J. R. (1980). A Manual for Genetic Engineering: Advanced Bacterial Genetics. New York: Cold Spring Harbor Laboratory

Downing, R. \& Broda, P. (1979). A cleavage map of the TOL plasmid of Pseudomonas putida mt-2. Molecular and General Genetics 177, 189-191.

Hegesan, G. D. (1966). Synthesis of enzymes of the mandelate pathway by Pseudomonas putida. I. Synthesis of enzymes by the wild type. Journal of Bacteriology 91, 1140-1154.

Hopper, D. J. \& Chapman, P. J. (1971). Gentisic acid and its 3- and 4-methyl-substituted homologues as intermediates in the bacterial degradation of $m$ - cresol, 3,5-xylenol and 2,5-xylenol. Biochemical Journal 122, $19-28$.

HOPPER, D. J. \& KEMP, P. D. (1980). Regulation of enzymes of the 3,5-xylenol degradative pathway in Pseudomonas putida: evidence for a plasmid. Journal of Bacteriology 142, 21-26.

Hopper, D. J. \& TAYLoR, D. G.(1975). Pathways for the degradation of $m$-cresol and $p$-cresol by Pseudomonas putida. Journal of Bacteriology 122, 1-6.

Hopper, D. J., Chapman, P. J. \& Dagley, S. (1971). The enzymic degradation of alkyl-substituted gentisates, maleates and malates. Biochemical Journal 122, $29-40$.

Johnson, P. H. \& Grossman, L. I. (1977). Electrophoresis of DNA in agarose gels. Optimizing separation of conformational isomers of double and single stranded DNAs. Biochemistry 16, 4217-4225.

KeAT, M. J. \& HoPPER, D. J. (1978a). p-Cresol and 3,5xylenol methylhydroxylases in Pseudomonas putida NCIB 9869. Biochemical Journal 175, 649-658.

KEAT, M. J. HOPPER, D. J. (1978b). The aromatic alcohol dehydrogenases in Pseudomonas putida NCIB 9869 grown on 3,5-xylenol and p-cresol. Biochemical Journal 175, 659-667.

LACK, L. (1961). Enzymic cis-trans isomerization of maleylpyruvic acid. Journal of Biological Chemistry 236. 2835-2840.

Pickup, R. W. \& Williams, P. A. (1982). Spontaneous deletions in the TOL plasmid pWW 20 which give rise to the B3 regulatory mutants of Pseudomonas putida MT20. Journal of General Microbiology 128. 1385-1390.

Pickup, R. W., Lewis, R. J. \& Williams, P. A. (1983). Pseudomonas sp. MT14, a soil isolate which contains two large catabolic plasmids, one a TOL plasmid and one coding for phenylacetate catabolism and mer- 
cury resistance. Journal of General Microbiology 129. 153-158.

Poh, C. L. \& BAyly, R. C. (1980). Evidence for isofunctional enzymes used in $m$-cresol and 2,5-xylenol degradation via the gentisate pathway in Pseudomonas alcaligenes. Journal of Bacteriology 143, 59-69. RAY, A. \& SKurkaY, R. (1983). Cloning and polypeptide analysis of the leading region in F plasmid DNA transfer. Plasmid 9, 262-272.
Tanaka, H., Sugtyama, S., Yano, K. A ARIma, K. (1957). Isolation of fumarylpyruvic acid as an intermediate of the gentisic acid oxidation by Pseudomonas ovalis var. S-5. Bulletin of the Agricultural Chemical Society of Japan 21, 67-68.

Wheatcroft, R. \& Willans, P. A. (1981). Rapid methods for the study of both stable and unstable plasmids in Pseudomonas. Journal of General Microbiology 124, 433-437. 